\title{
Hydrogen Storage and Release Properties of a Cu-Added Fe/YSZ Redox System
}

\author{
Hyo-Sub Kim, ${ }^{1}$ Dong-Hee Lee, ${ }^{1}$ Hong-Soon Kim, ${ }^{1}$ Chu-Sik Park, ${ }^{2}$ and Young-Ho Kim ${ }^{1}$ \\ ${ }^{1}$ Department of Fine Chemical Engineering and Applied Chemistry, Chungnam National University, 220 Gung-dong, Yuseong-gu, \\ Daejeon 305-764, Republic of Korea \\ ${ }^{2}$ Hydrogen Energy Research Group, Korea Institute of Energy Research, 71-2 Jang-dong, Yuseong-gu, \\ Daejeon 305-343, Republic of Korea
}

Correspondence should be addressed to Young-Ho Kim; yh_kim@cnu.ac.kr

Received 13 August 2013; Accepted 24 November 2013

Academic Editor: Jae-Ho Kim

Copyright (C) 2013 Hyo-Sub Kim et al. This is an open access article distributed under the Creative Commons Attribution License, which permits unrestricted use, distribution, and reproduction in any medium, provided the original work is properly cited.

Hydrogen storage and release by the redox reaction of an iron oxide with yttria-stabilized zirconia (YSZ) were investigated. YSZ was introduced to the samples to improve the thermal stability of the iron oxide. The average size of the samples synthesized using urea was $40-50 \mathrm{~nm}$, whereas those synthesized using $\mathrm{Na}_{2} \mathrm{CO}_{3}$ as a precipitant were $150-200 \mathrm{~nm}$. The sample prepared via coprecipitation using urea exhibited better stability than the other samples. We prepared the Cu-added Fe/YSZ sample to enhance the lowtemperature reactivity. The water-splitting reaction was initiated at approximately $200^{\circ} \mathrm{C}$, and the maximum rate of hydrogen evolution was observed at approximately $350^{\circ} \mathrm{C}$. In the isothermal redox test over 35 cycles, the degree of hydrogen storage and release was almost maintained over $1.8 \mathrm{wt} \%$ based on the total amount of the sample.

\section{Introduction}

Hydrogen production, storage, and utilization have been widely studied in an effort to solve the depletion of fossil fuels and environmental problems $[1,2]$. Hydrogen can be produced from various processes such as the steam methane reforming, water electrolysis, gasification of coal and biomass, and water splitting by high temperature heat [3]. The hydrogen storage technologies are the physical storage methods, such as compressed gas storage and liquid storage, and the chemical storage methods, such as metal hydrides and chemical hydrides $[4,5]$. Among the various methods of hydrogen utilization, the polymer electrolyte membrane fuel cell (PEMFC) is well known to be the most suitable for automobile applications due to high power density and quick start-up. The hydrogen for operating the PEMFC requires the very low tolerance of $\mathrm{CO}$ that affects the Pt catalyst by the poisoning. Otsuka et al. [6] proposed a system for the chemical storage and release of hydrogen to supply $\mathrm{CO}$ free hydrogen to the PEMFC. The concept of this system is consistent with the conventional steam-iron process using the redox reaction of iron oxide. The first step in this system involves the reduction of $\mathrm{Fe}_{3} \mathrm{O}_{4}$ using hydrogen (1). In the second step, the $\mathrm{Fe}$ is oxidized by water vapor (2) as follows:

Step 1. Hydrogen reduction (hydrogen storage)

$$
\mathrm{Fe}_{3} \mathrm{O}_{4}+4 \mathrm{H}_{2} \longrightarrow 3 \mathrm{Fe}+4 \mathrm{H}_{2} \mathrm{O}
$$

Step 2. Water-splitting oxidation (hydrogen release)

$$
3 \mathrm{Fe}+4 \mathrm{H}_{2} \mathrm{O} \longrightarrow \mathrm{Fe}_{3} \mathrm{O}_{4}+4 \mathrm{H}_{2}
$$

The theoretical quantity of stored hydrogen is $4.8 \mathrm{wt} \%$ based on $1 \mathrm{~g} \mathrm{Fe}$ in this system. A high temperature (approximately $400^{\circ} \mathrm{C}$ ) is required for the hydrogen evolution step. The iron oxide exhibits low stability because the particles aggregate during the reactions causing a deactivation. To prevent this deactivation, many researchers have investigated the thermal stability and reactivity by introducing foreign metals or metal oxides. Ostuka et al. [6] reported that Ga, V, $\mathrm{Cr}$, and $\mathrm{Mo}$ are favorable additives for accelerating the redox reaction. Takenaka et al. [7] reported that $\mathrm{Rh}$ enhances the rate of hydrogen formation for iron oxides and Mo prevents the sintering of the iron particles. In addition, Wang et al. [8] 


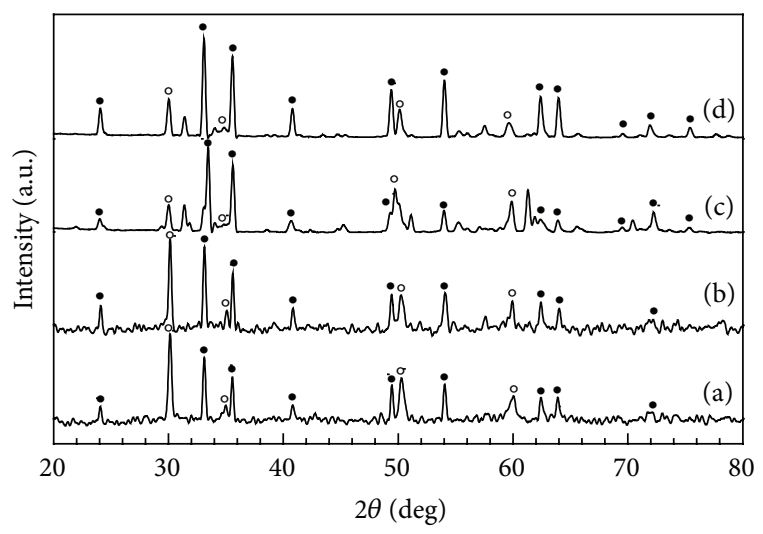

FIGURE 1: XRD patterns of the samples after calcination: (a) Fe/YSZ1, (b) Fe/YSZ-2, (c) Fe/YSZ-3, and (d) Fe/YSZ-4 (•: $\mathrm{Fe}_{2} \mathrm{O}_{3}$, O: YSZ).

reported that adding Mo to the iron oxide could improve the rate of hydrogen formation.

In our previous work [9-12], we investigated the effect of $\mathrm{Zr}$-based mixed oxides (i.e., $\mathrm{ZrO}_{2}, \mathrm{CeO}_{2}$, or $\mathrm{Ce}-\mathrm{ZrO}_{2}$ ) as promising supporters or binders for preventing the aggregation of iron oxide during the redox reaction. Yttriastabilized zirconia (YSZ) is reportedly a promising catalyst or supporting material due to its high thermal stability and its stability under reducing and oxidizing gas conditions [13-15].

This work examines the effects of adding YSZ on the redox behavior of iron oxide. We introduced YSZ into the iron oxide to enhance its thermal stability in the redox reaction. The effect of varying the yttria concentration in the iron oxide on the redox reaction behaviors was investigated. The reduction and oxidation studies were carried out via $\mathrm{TPR} / \mathrm{O}$ (temperature-programmed reduction/oxidation) in a fixed-bed reactor. In addition, we added $\mathrm{Cu}$ into the $\mathrm{Fe} / \mathrm{YSZ}$ sample to improve its low-temperature reactivity for the water-splitting reaction.

\section{Experimental}

2.1. Sample Preparation. Analytical grade $\mathrm{Fe}\left(\mathrm{NO}_{3}\right)_{3} \cdot 9 \mathrm{H}_{2} \mathrm{O}$ (99\%, Kanto), $\mathrm{Cu}\left(\mathrm{NO}_{3}\right)_{2} \cdot 3 \mathrm{H}_{2} \mathrm{O}$ (99\%, Junsei), $\mathrm{Y}\left(\mathrm{NO}_{3}\right)_{3}$ . $6 \mathrm{H}_{2} \mathrm{O}$ (99.9\%, Aldrich), and $\mathrm{Zr}\left(\mathrm{OCH}_{2} \mathrm{CH}_{2} \mathrm{CH}_{3}\right)_{4}$ (70 wt\%, Aldrich) served as sources of the metal precursor of $\mathrm{Fe}, \mathrm{Cu}, \mathrm{Y}$ (yttrium), and Zr, respectively. The concentration of the YSZ in the $\mathrm{Fe} / \mathrm{YSZ}$ samples was maintained at $40 \mathrm{wt} \%$. We used a urea and $\mathrm{Na}_{2} \mathrm{CO}_{3}$ solution as a precipitant and prepared the samples using the coprecipitation and impregnation method.

For the coprecipitation method, the samples were prepared as follows. A urea solution was added dropwise to the metal precursor solutions at $90^{\circ} \mathrm{C}$ over $2 \mathrm{~h}$ with stirring. The precipitate was washed three times with deionized water and dried at $100^{\circ} \mathrm{C}$ for $24 \mathrm{~h}$ and then calcined under air at $900^{\circ} \mathrm{C}$. For the $\mathrm{Na}_{2} \mathrm{CO}_{3}$ solution, the precursor and precipitant solutions were added together dropwise at $2^{\circ} \mathrm{C}$ under strong stirring.

Other samples were prepared via the impregnation method using the as-synthesized YSZ powder. A solution containing the YSZ mixed with the Fe precursor at $60^{\circ} \mathrm{C}$ was decompressed, and the urea or $\mathrm{Na}_{2} \mathrm{CO}_{3}$ solution was added dropwise. The products were washed and dried using the previously described procedure.

The prepared samples were denoted as Fe/YSZ-1 (coprecipitation and urea), Fe/YSZ-2 (impregnation method and urea), $\mathrm{Fe} / \mathrm{YSZ}-3$ (coprecipitation and $\mathrm{Na}_{2} \mathrm{CO}_{3}$ ), and Fe-YSZ4 (impregnation method and $\mathrm{Na}_{2} \mathrm{CO}_{3}$ ) depending on the preparation method and type of the precipitant.

2.2. Sample Evaluation. We evaluated the redox reactions for the as-prepared samples in a conventional gas-flow system with a fixed-bed quartz reactor. The sample $(0.5 \mathrm{~g})$ was charged into the center of the reactor. Hydrogen gas $\left(10 \% \mathrm{H}_{2}\right.$, Ar balance) was introduced into the reactor at a flow rate of $40 \mathrm{~mL} \mathrm{~min}^{-1}$ and heated at $10^{\circ} \mathrm{C} \mathrm{min}^{-1}$ from room temperature to $550^{\circ} \mathrm{C}$ for the reduction step. For the subsequent water-splitting oxidation step, water vapor was introduced into the reactor with an Ar carrier gas at a total flow rate of $40 \mathrm{~mL} \mathrm{~min}^{-1}$; the water vapor partial pressure was approximately $32 \mathrm{kPa}$, and the heating rate was $10^{\circ} \mathrm{C} \mathrm{\textrm {min } ^ { - 1 }}$ from room temperature to $600^{\circ} \mathrm{C}$. The temperature was maintained until no hydrogen peak was detected during both the reduction and oxidation reactions. The hydrogen gas was analyzed using a gas chromatograph (Donam, DS6200) equipped with a thermal conductivity detector (TCD). Based on the TPR/O profiles, a temperature of $550^{\circ} \mathrm{C}$ was selected for the hydrogen reduction and $350^{\circ} \mathrm{C}$ was selected for the water-splitting oxidation in the isothermal cyclic test. The crystallinity of the samples was characterized via X-ray diffraction (XRD, Rigaku Dmax 2500). We also observed the particle size and morphology of the samples via scanning electron microscopy (SEM, Hitachi, S-4700).

\section{Results and Discussion}

3.1. Effects of the Preparation Method. Figure 1 presents the XRD patterns of the Fe/YSZ samples, all of which demonstrate that the assignable lines originated from the $\mathrm{Fe}_{2} \mathrm{O}_{3}$ and cubic-structured YSZ phases. In addition, no mixing of the Fe, Y (yttrium), and $\mathrm{Zr}$ was detected. The patterns for pure $\mathrm{ZrO}_{2}$ exhibit tetragonal or monoclinic structures below the calcination temperature of $2,370^{\circ} \mathrm{C}$, but a cubic structure was noted in the presence of Y (yttrium) at low temperature. This result indicates that the cubic-structured YSZ was successfully synthesized. Figure 2 provides the SEM images of the as-prepared samples. The particle sizes were approximately $40-50 \mathrm{~nm}$ when urea was used as the precipitant but approximately $150-200 \mathrm{~nm}$ when $\mathrm{Na}_{2} \mathrm{CO}_{3}$ was used. Given this finding, we concluded that the particle size was strongly affected by the precipitant but not by the precipitation method.

The TPR/O profiles of the as-prepared samples are presented in Figure 3. In the first reduction step, TPR profiles typical of $\mathrm{Fe}_{2} \mathrm{O}_{3}$ were observed [9]. Although the reduction was initiated at approximately $300^{\circ} \mathrm{C}$, the peaks were primarily observed at approximately $350-500^{\circ} \mathrm{C}$ and $550^{\circ} \mathrm{C}$. These peaks were attributed to a reduction of the $\mathrm{Fe}_{2} \mathrm{O}_{3}$ to $\mathrm{Fe}_{3} \mathrm{O}_{4}$ and subsequently to metallic $\mathrm{Fe}$ (see(3) and (4)). To 


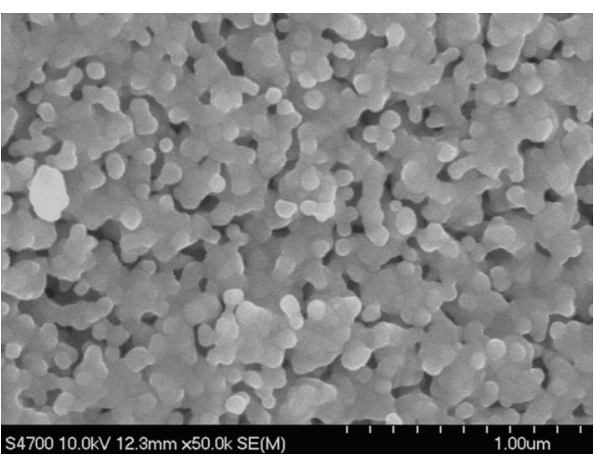

(a)

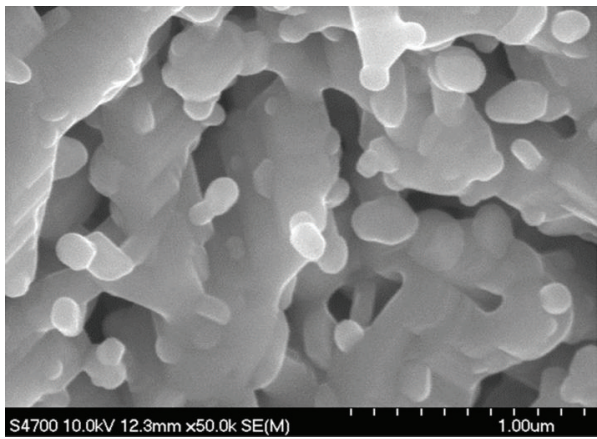

(c)

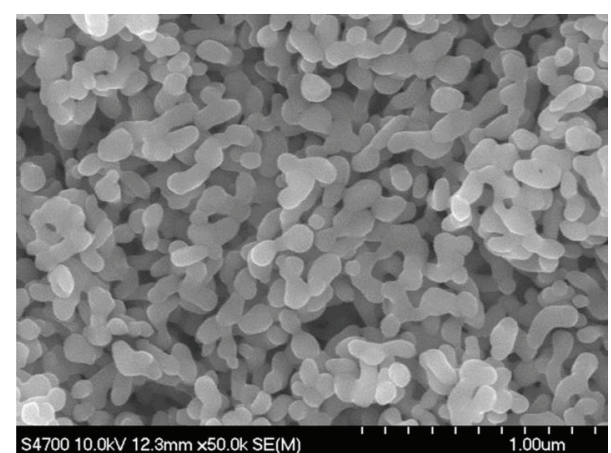

(b)

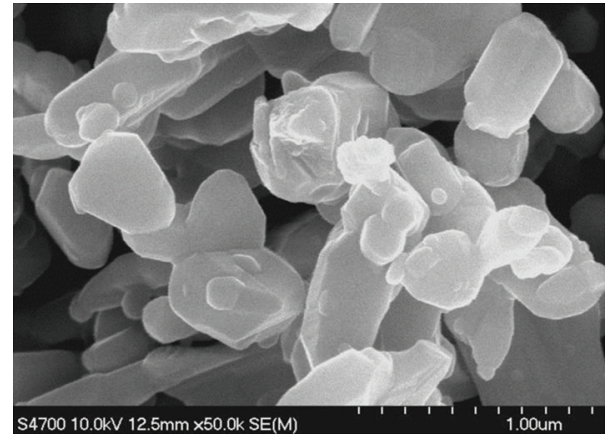

(d)

FIGURE 2: SEM images of the samples after calcination: (a) Fe/YSZ-1, (b) Fe/YSZ-2, (c) Fe/YSZ-3, and (d) Fe/YSZ-4.

Reduction

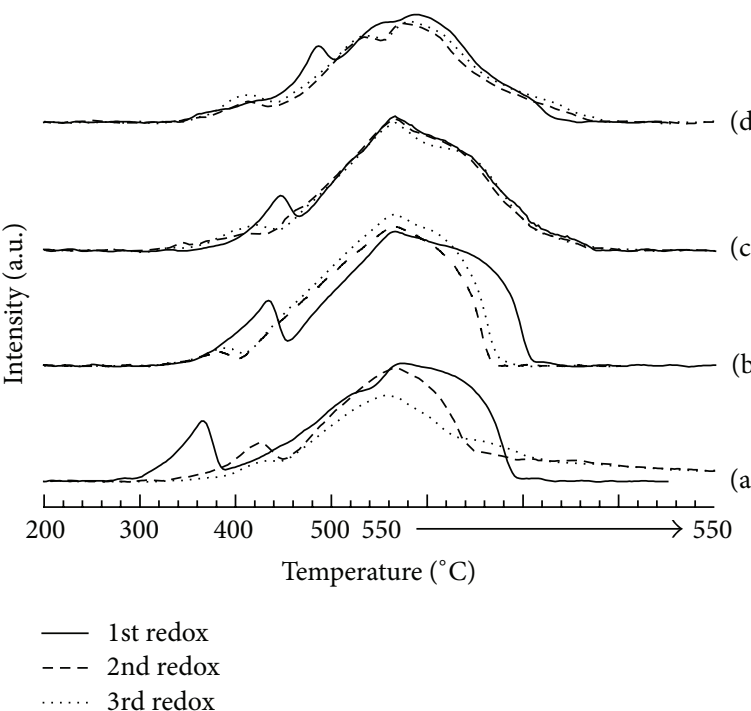

Oxidation

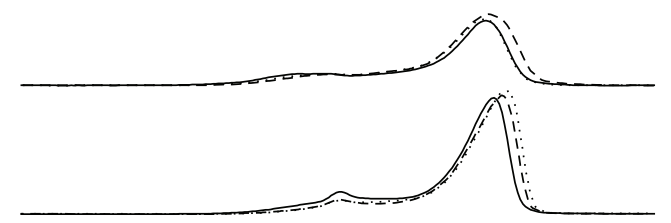

(b)

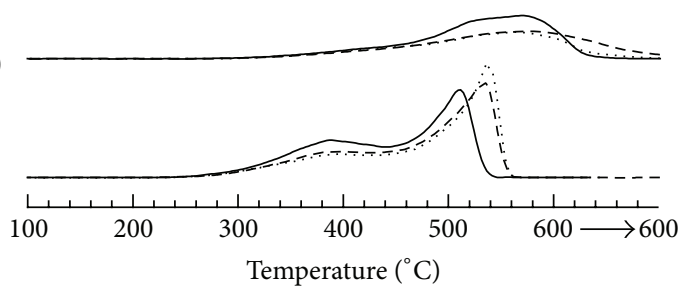

FIGURE 3: TPR/O profiles of the as-prepared samples during three repeated redox cycles: (a) Fe/YSZ-1, (b) Fe/YSZ-2, (c) Fe/YSZ-3, and (d) Fe/YSZ-4.

determine the degree of reduction, the ratio of the first and second peaks in the TPR profiles was calculated as $1: 8$ for the complete reduction [16]

$$
3 \mathrm{Fe}_{2} \mathrm{O}_{3}+1 \mathrm{H}_{2} \longrightarrow 2 \mathrm{Fe}_{3} \mathrm{O}_{4}+1 \mathrm{H}_{2} \mathrm{O}
$$

$$
2 \mathrm{Fe}_{3} \mathrm{O}_{4}+8 \mathrm{H}_{2} \longrightarrow 6 \mathrm{Fe}+8 \mathrm{H}_{2} \mathrm{O}
$$

The ratios of the areas of the first and second peaks were calculated at approximately $11-12 \%$ for all samples, which indicates that most of the $\mathrm{Fe}_{2} \mathrm{O}_{3}$ was completely reduced to metallic Fe by hydrogen during the first reduction. 

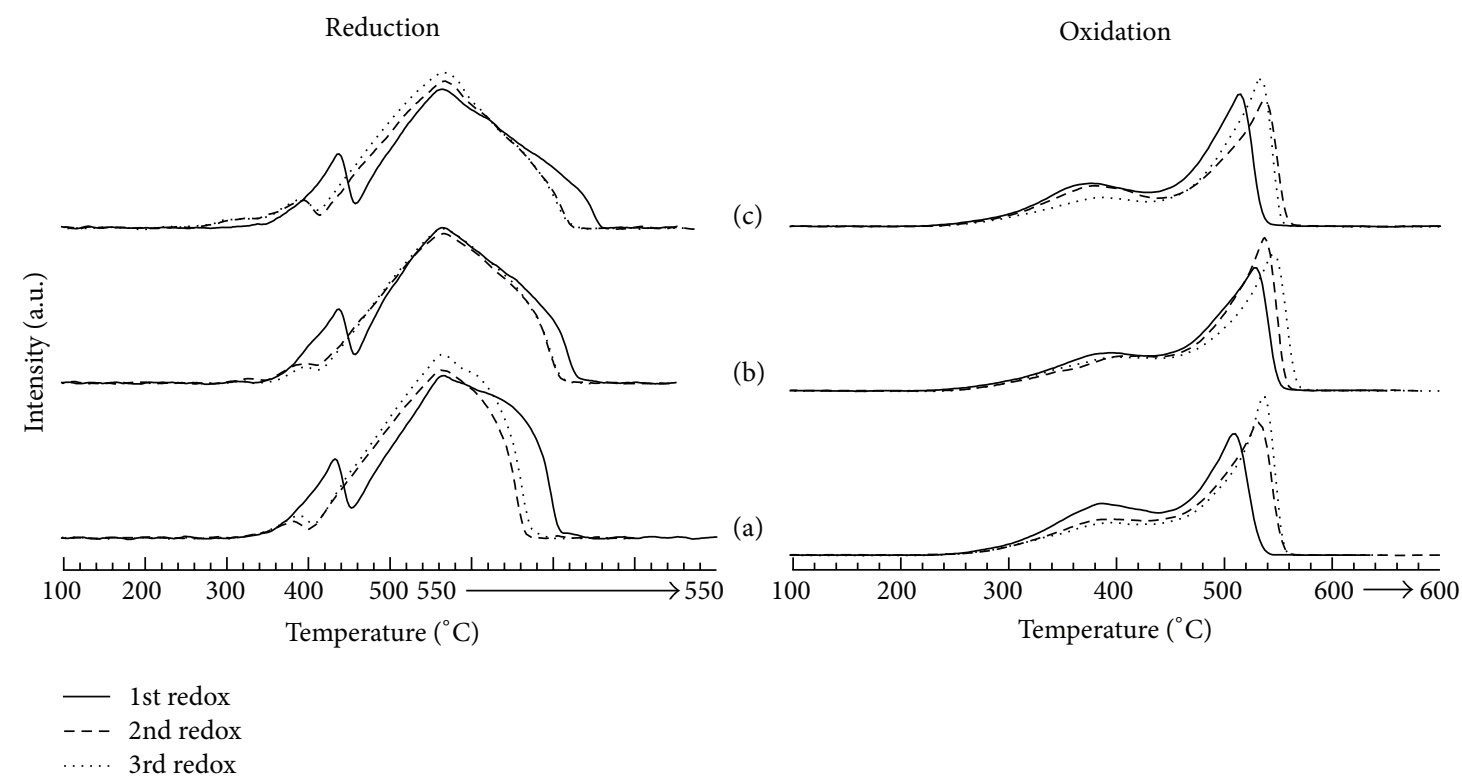

FIGURE 4: TPR/O profiles of the Fe/ $x$ YSZ ( $x=4,8$, and 12) samples during three repeated redox cycles: (a) Fe/4YSZ, (b) Fe/8YSZ, and (c) $\mathrm{Fe} / 12 \mathrm{YSZ}$.

TABLE 1: The quantities of hydrogen consumed and evolved in the TPR/O test during three repeated cycles.

\begin{tabular}{|c|c|c|c|c|c|c|c|}
\hline Sample & $\operatorname{Max}^{\mathrm{a}}$ & 1 st $\operatorname{Red}^{\mathrm{b}}$ & 1st $\mathrm{Oxi}^{\mathrm{c}}$ & 2nd Red & 2nd Oxi & 3rd Red & 3rd Oxi \\
\hline Fe/YSZ-1 & \multirow{4}{*}{10.36} & 10.16 & 8.89 & 9.07 & 8.93 & 10.23 & 8.84 \\
\hline $\mathrm{Fe} / Y S Z-2$ & & 9.51 & 6.41 & 8.68 & 5.62 & 7.36 & 4.65 \\
\hline Fe/YSZ-3 & & 9.86 & 8.46 & 9.35 & 8.25 & 9.23 & 8.87 \\
\hline $\mathrm{Fe} / \mathrm{YSZ}-4$ & & 8.05 & 6.12 & 9.23 & 5.96 & 7.65 & 6.97 \\
\hline
\end{tabular}

${ }^{\mathrm{a}}$ Quantity of hydrogen consumed when $1 \mathrm{~g}$ of sample was theoretically reduced in the first reduction ( $\mathrm{mmol} \mathrm{g}^{-1}$-sample).

${ }^{\mathrm{b}}$ Quantity of hydrogen consumed during the reduction step ( $\mathrm{mmol} \mathrm{g}^{-1}$-sample).

${ }^{c}$ Quantity of hydrogen evolved during water-splitting step ( $\mathrm{mmol} \mathrm{g}^{-1}$-sample).

TABLE 2: The hydrogen evolution rate for the samples during isothermal redox cycles.

\begin{tabular}{lcccccc}
\hline \multirow{2}{*}{ Sample } & \multicolumn{6}{c}{ Hydrogen evolution rate ${ }^{\mathrm{a}}\left(\mathrm{mmol} \mathrm{min}^{-1} \mathrm{~g}^{-1}\right.$-sample) } \\
& 1st & 2nd & 3rd & 4th & 5th & Avg. \\
\hline Fe/YSZ-1 & 1.07 & 0.95 & 0.92 & 0.87 & 0.97 & 0.96 \\
Fe/YSZ-2 & 0.19 & 0.14 & 0.1 & 0.12 & 0.10 & 0.13 \\
Fe/YSZ-3 & 0.70 & 0.63 & 0.71 & 0.79 & 0.75 & 0.72 \\
Fe/YSZ-4 & 0.58 & 0.56 & 0.44 & 0.42 & 0.44 & 0.49 \\
\hline
\end{tabular}

${ }^{\mathrm{a}}$ Quantity of hydrogen evolved divided by the time required for complete oxidation.

Although the oxidation reactions were initiated at approximately $250^{\circ} \mathrm{C}$, the maximum peaks were observed in the TPO profiles between $520^{\circ} \mathrm{C}$ and $550^{\circ} \mathrm{C}$ for all samples. The Fe/YSZ-2 sample exhibits a relatively low peak intensity and longer reaction time, indicating that the reactivity of the Fe/YSZ-2 was low. The quantities of hydrogen consumed and evolved were calculated (Table 1). Under the theoretical conditions, $10.36 \mathrm{mmol} \mathrm{g}^{-1}$-sample hydrogen can be consumed during the first reduction step and $9.21 \mathrm{mmolg}^{-1}$ sample hydrogen can be evolved in the corresponding reaction step. Although approximately $90-95 \%$ of the iron oxide participated during the oxidation reaction with the Fe/YSZ-1 and Fe/YSZ-3 samples, only approximately 50$65 \%$ of the iron oxide participated in the reaction with the Fe/YSZ-2 and Fe/YSZ-4 samples. The quantity of hydrogen evolved with the Fe/YSZ-2 gradually decreased from 6.41 to $4.65 \mathrm{mmol} \mathrm{g}^{-1}$-sample during the reaction, indicating a substantial deactivation of this sample. It was interesting that the reactivity of Fe/YSZ-2 sample decreased during the reaction, although the XRD patterns and particle sizes of $\mathrm{Fe} / \mathrm{YSZ}-1$ and Fe/YSZ-2 were very similar as shown in Figures 1 and 2. It indicates that the coprecipitation method was more effective in inhibiting sintering of the sample than the impregnation method, because the iron oxide and YSZ were well mixed in the crystal growth step via coprecipitation.

An isothermal reduction/oxidation was conducted to compare the hydrogen evolution rates of the samples (Table 2). Using the results of the TPR/O profiles, the temperature for the reduction and oxidation was fixed at $550^{\circ} \mathrm{C}$. Among the as-prepared samples, Fe/YSZ-1 demonstrates the highest hydrogen evolution rate. The rate of hydrogen evolution decreased in the following order: Fe/YSZ-3 > Fe/YSZ$4>\mathrm{Fe} / \mathrm{YSZ}-2$. We concluded that a preparation method via 


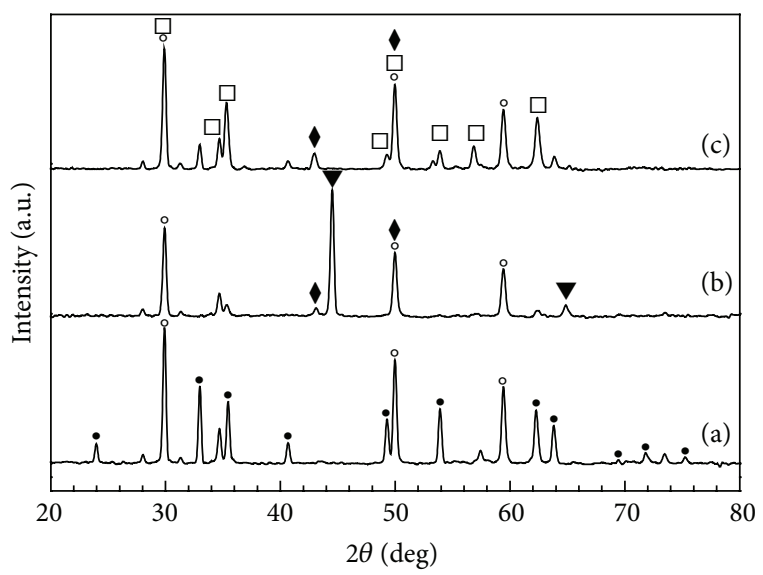

FIGURE 5: XRD patterns of the samples (a) before the reaction with $\mathrm{Cu} / \mathrm{Fe} / 12 \mathrm{YSZ}$, (b) after the first reduction of (a), and (c) after the first oxidation of (b) $\left(\bullet: \mathrm{Fe}_{2} \mathrm{O}_{3}, \mathrm{O}: \mathrm{YSZ}, \boldsymbol{\nabla}: \mathrm{Fe}, \square: \mathrm{Fe}_{3} \mathrm{O}_{4}, \diamond: \mathrm{Cu}\right)$.

the coprecipitation using a urea solution was favorable to maintain reactivity.

3.2. Effects of the Yttria Concentrations. The effects of the yttria concentrations $(4,8$, and $12 \mathrm{~mol} \%$ of the total metal cations in the YSZ) on the redox reactivity were investigated. The samples were prepared via the coprecipitation using urea and were designated as Fe/ $x$ YSZ $(x=4,8$, and 12). Figure 4 presents the TPR/O profiles for the as-prepared Fe/ $x \mathrm{YSZ}$ samples. Although typical hydrogen reduction profiles were observed for all samples at a similar temperature, the total reaction time increased with increasing yttria concentration. In the TPO profiles, the temperatures at which oxidation was initiated decreased slightly as the yttria concentration increased.

The isothermal reactions profiles of the oxidation step for each sample over 5 cycles are listed in Table 3 . The temperatures for the reduction and oxidation were maintained until the hydrogen peaks were no longer observed. The quantities of evolved hydrogen were similar in all samples (approximately $9-10 \mathrm{mmolg}^{-1}$-sample). As the yttria concentration increased, the total oxidation time and the rate of hydrogen evolution decreased. Therefore, the Fe/12YSZ sample exhibited the highest hydrogen evolution rate.

\subsection{Effects of the $\mathrm{Cu}$ Additive on the Isothermal Reactivity.} In our previous study, mixing the $\mathrm{Fe}_{3} \mathrm{O}_{4}$ with $\mathrm{Ce}-\mathrm{ZrO}_{2}$ [12] accelerated the water-splitting reaction at low temperatures in the presence of a $\mathrm{Cu}$ additive. Although the reactivity was maintained during the test, the temperature for the water splitting with $\mathrm{Fe} / \mathrm{YSZ}$ was relatively high $\left(>500^{\circ} \mathrm{C}\right)$. To improve the low-temperature reactivity of the water-splitting step $\left(<350^{\circ} \mathrm{C}\right)$, we introduced a small quantity of $\mathrm{Cu}$ into the $\mathrm{Fe} / \mathrm{YSZ}$.

We prepared the $3 \mathrm{wt} \% \mathrm{Cu}$-added Fe/12YSZ sample, designated as $\mathrm{Cu} / \mathrm{Fe} / 12 \mathrm{YSZ}$, via the coprecipitation method using urea. The XRD peak for the Cu/Fe/12YSZ (Figure 5(a)) corresponding to $\mathrm{Fe}_{2} \mathrm{O}_{3}$ (hematite) and cubic-structured YSZ was similar to that in Figure 1(a), indicating that the $\mathrm{Cu}$ added iron oxide existed as $\mathrm{Cu}_{x} \mathrm{Fe}_{3-x} \mathrm{O}_{4}(x<1)$ [17]. After the oxidation, metallic $\mathrm{Cu}$ and $\mathrm{Fe}_{3} \mathrm{O}_{4}$ phases were observed (Figure 5(c)).

Figure 6 provides the TPR/O profiles for the $\mathrm{Cu} / \mathrm{Fe} / 12 \mathrm{YSZ}$ and Fe/12YSZ samples. The reduction reaction for the $\mathrm{Cu} / \mathrm{Fe} / 12 \mathrm{YSZ}$ sample was initiated at approximately $200^{\circ} \mathrm{C}$, and the main reduction peaks were observed at approximately $300^{\circ} \mathrm{C}$ and $500^{\circ} \mathrm{C}$. We also observed a distinct effect on the oxidation reaction with the addition of $\mathrm{Cu}$. The initiation temperature for the oxidation of $\mathrm{Cu} / \mathrm{Fe} / 12 \mathrm{YSZ}$ decreased by approximately $200^{\circ} \mathrm{C}$ with the maximum hydrogen evolution observed at approximately $350^{\circ} \mathrm{C}$. The $\mathrm{Cu}$ additive improved the low-temperature reduction and oxidation reactivity.

The reduction and oxidation temperatures for the isothermal redox reaction were maintained at $550^{\circ} \mathrm{C}$ and $350^{\circ} \mathrm{C}$ depending on the TPR/O results. We performed the isothermal redox tests for 35 cycles to identify the cycle stability of the $\mathrm{Cu} / \mathrm{Fe} / 12 \mathrm{YSZ}$ sample (Figure 7 ). The results can be divided into two sections: the reactions prior to the 10th cycle and those between the 11th and 30th cycles. For the first section, the hydrogen evolution rate was high and the quantities of evolved hydrogen were over $9 \mathrm{mmolg}^{-1}$. sample. After the 10th cycle, the hydrogen evolution rate and the quantity of evolved hydrogen decreased and remained stable for the reactions between the 11th and 30th cycles. Approximately $8 \mathrm{mmol} \mathrm{g}^{-1}$-sample hydrogen was evolved in the second section, which indicates a hydrogen storage of $1.8 \mathrm{wt} \%$ based on the $\mathrm{Cu} / \mathrm{Fe} / 12 \mathrm{YSZ}$ sample.

After the 30th cycle, we collected the reacted sample and ground it with a mortar to regenerate the $\mathrm{Cu} / \mathrm{Fe} / 12 \mathrm{YSZ}$ material. The isothermal redox tests were conducted for 5 cycles by charging the ground sample. The quantity of hydrogen evolved in the regeneration step was maintained at approximately $8 \mathrm{mmol} \mathrm{g}^{-1}$-sample. In addition, the rate of hydrogen evolution was approximately $9 \mathrm{mmol} \mathrm{min}^{-1} \mathrm{~g}^{-1}$ sample. These values were similar to those obtained prior to the regeneration step, indicating that the regeneration process restores the sample reactivity.

Figure 8 provides the SEM images of the $\mathrm{Cu} / \mathrm{Fe} / 12 \mathrm{YSZ}$ sample both before the reaction and after the 35th redox cycle. The average size of the $\mathrm{Cu} / \mathrm{Fe} / 12 \mathrm{YSZ}$ was approximately 30 $40 \mathrm{~nm}$ (Figure 8(a)). After the 35th redox cycle, aggregated $\mathrm{Cu} / \mathrm{Fe} / 12 \mathrm{YSZ}$ particles were observed (Figure $8(\mathrm{~b})$ ). The decrease in the rate of hydrogen evolution and the quantity of hydrogen evolved with $\mathrm{Cu} / \mathrm{Fe} / 12 \mathrm{YSZ}$ was attributed to the deactivation due to particle aggregation.

\section{Conclusions}

We investigated the hydrogen storage and release characteristics of a YSZ-supported iron oxide sample using TPR/O and isothermal redox tests. Preparation via coprecipitation using urea was effective in maintaining the sample reactivity. Increasing the yttria concentration in the Fe/YSZ decreased the total oxidation time and the rate of hydrogen evolution. The introduction of a small quantity of $\mathrm{Cu}$ into the $\mathrm{Fe} / \mathrm{YSZ}$ enhanced the low-temperature reduction and oxidation reactivity. The isothermal redox tests yielded the hydrogen storage 
TABLE 3: Total oxidation time, quantities of evolved hydrogen, and the hydrogen evolution rate with Fe/4YSZ, Fe/8YSZ, and Fe/12YSZ during five repeated isothermal redox cycles.

\begin{tabular}{|c|c|c|c|c|c|c|c|}
\hline & Sample & 1st & 2nd & $3 \mathrm{rd}$ & 4th & 5 th & Avg. \\
\hline \multirow{3}{*}{$\mathrm{a}$} & $\mathrm{Fe} / 4 \mathrm{YSZ}$ & 10.00 & 10.50 & 11.25 & 11.00 & 10.50 & 10.65 \\
\hline & Fe/8YSZ & 9.75 & 10.50 & 10.50 & 10.75 & 9.75 & 10.25 \\
\hline & $\mathrm{Fe} / 12 \mathrm{YSZ}$ & 7.75 & 8.75 & 9.00 & 9.50 & 9.50 & 8.90 \\
\hline \multirow{3}{*}{$\mathrm{b}$} & $\mathrm{Fe} / 4 \mathrm{YSZ}$ & 10.16 & 9.95 & 9.93 & 10.01 & 9.93 & 10.00 \\
\hline & Fe/8YSZ & 9.61 & 9.70 & 9.45 & 9.85 & 9.57 & 9.64 \\
\hline & $\mathrm{Fe} / 12 \mathrm{YSZ}$ & 9.62 & 9.61 & 9.93 & 10.02 & 9.94 & 9.82 \\
\hline \multirow{3}{*}{$c$} & $\mathrm{Fe} / 4 \mathrm{YSZ}$ & 1.02 & 0.95 & 0.88 & 0.91 & 0.95 & 0.94 \\
\hline & Fe/8YSZ & 0.99 & 0.92 & 0.90 & 0.92 & 0.98 & 0.94 \\
\hline & $\mathrm{Fe} / 12 \mathrm{YSZ}$ & 1.24 & 1.10 & 1.10 & 1.05 & 1.05 & 1.11 \\
\hline
\end{tabular}

(a) Total oxidation time (min).

(b) Quantity of hydrogen evolved ( $\mathrm{mmol} \mathrm{g}^{-1}$-sample).

(c) Quantity of hydrogen evolved divided by the time required for complete oxidation ( $\mathrm{mmol} \mathrm{min}^{-1} \mathrm{~g}^{-1}$-sample).

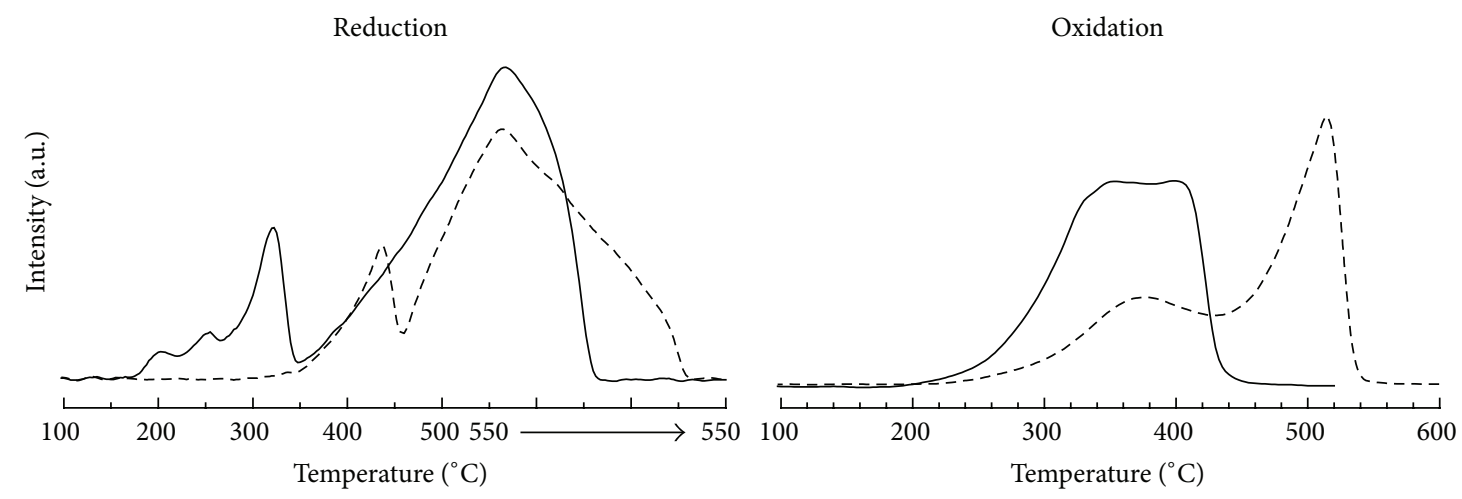

(a)

(b)

FIgURE 6: TPR/O profiles of the (a) Cu/Fe/12YSZ and (b) Fe/12YSZ.

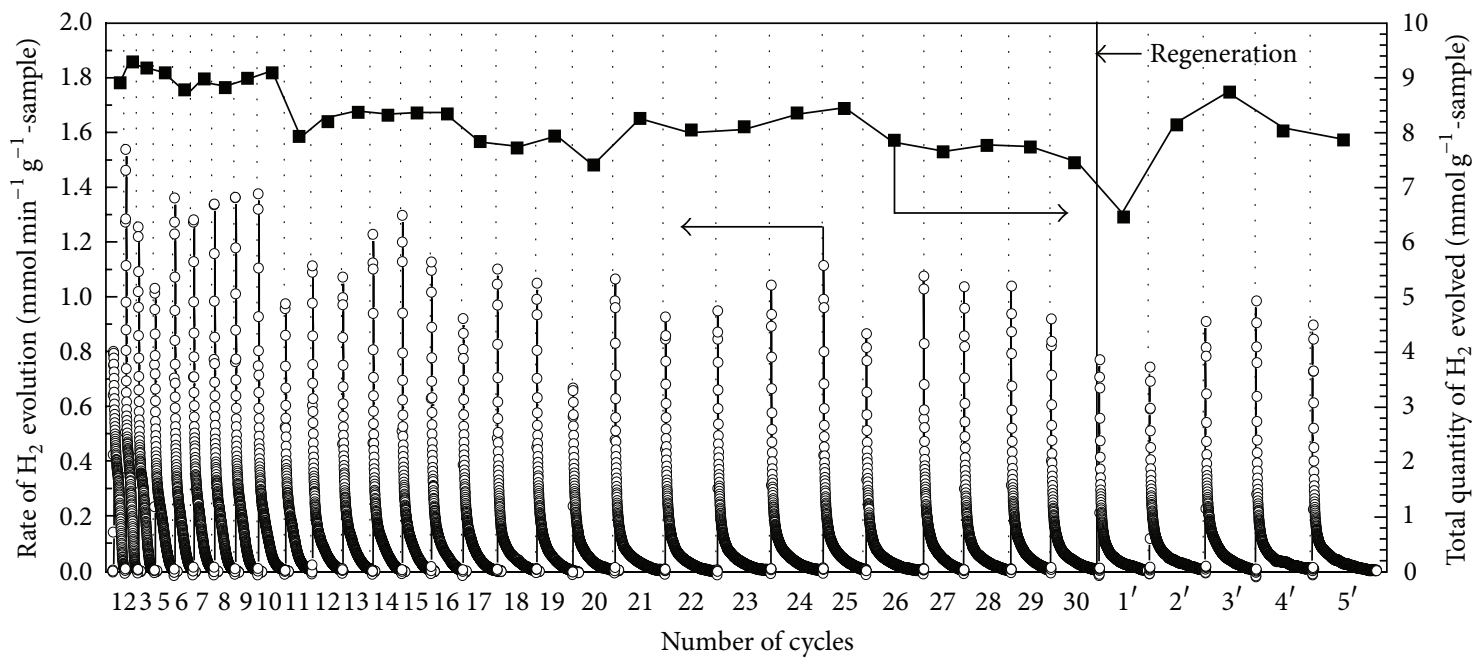

FIGURE 7: Isothermal oxidation profiles of the $\mathrm{Cu} / \mathrm{Fe} / 12 \mathrm{YSZ}$ during 35 redox cycles. 


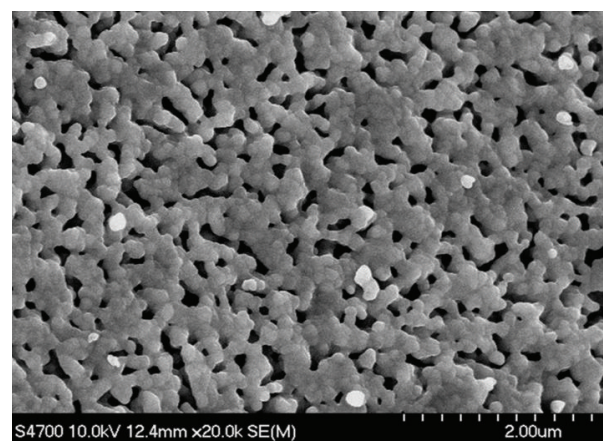

(a)

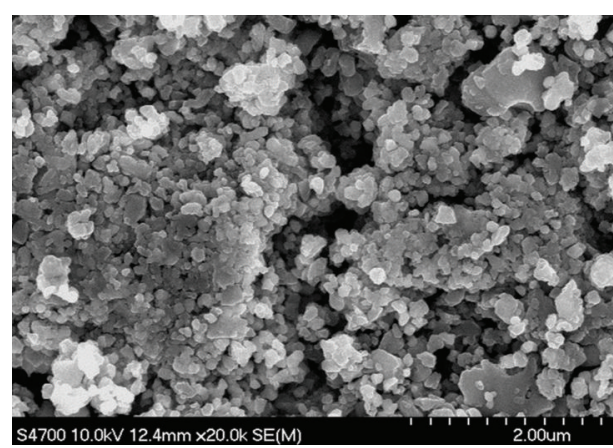

(b)

Figure 8: SEM images of the Cu/Fe/12YSZ sample (a) prior to the reaction and (b) after the 35th redox cycle.

of $1.8 \mathrm{wt} \%$ based on the $\mathrm{Cu} / \mathrm{Fe} / 12 \mathrm{YSZ}$ sample. In addition, the regeneration of the sample restores its reactivity.

\section{Conflict of Interests}

The authors declare that there is no conflict of interests regarding the publication of this paper.

\section{Acknowledgment}

This work was supported by research fund of Chungnam National University.

\section{References}

[1] V. Ananthachar and J. J. Duffy, "Efficiencies of hydrogen storage systems onboard fuel cell vehicles," Solar Energy, vol. 78, no. 5, pp. 687-694, 2005.

[2] P. Kruger, "Electric power requirement for large-scale production of hydrogen fuel for the world vehicle fleet," International Journal of Hydrogen Energy, vol. 26, no. 11, pp. 1137-1147, 2001.

[3] M. Ball and M. Wietschel, "The future of hydrogen-opportunities and challenges," International Journal of Hydrogen Energy, vol. 34, no. 2, pp. 615-627, 2009.

[4] G. Y. Moon, S. S. Lee, K. Y. Lee, S. H. Kim, and K. H. Song, "Behavior of hydrogen evolution of aqueous sodium borohydride solutions," Journal of Industrial and Engineering Chemistry, vol. 14, no. 1, pp. 94-99, 2008.

[5] J. J. Vajo and G. L. Olson, "Hydrogen storage in destabilized chemical systems," Scripta Materialia, vol. 56, no. 10, pp. 829834, 2007.

[6] K. Otsuka, C. Yamada, T. Kaburagi, and S. Takenaka, "Hydrogen storage and production by redox of iron oxide for polymer electrolyte fuel cell vehicles," International Journal of Hydrogen Energy, vol. 28, no. 3, pp. 335-342, 2003.

[7] S. Takenaka, T. Kaburagi, C. Yamada, K. Nomura, and K. Otsuka, "Storage and supply of hydrogen by means of the redox of the iron oxides modified with Mo and Rh species," Journal of Catalysis, vol. 228, no. 1, pp. 66-74, 2004.

[8] H. Wang, G. Wang, X. Wang, and J. Bai, "Hydrogen production by redox of cation-modified iron oxide," The Journal of Physical Chemistry C, vol. 112, no. 14, pp. 5679-5688, 2008.

[9] J. C. Ryu, D. H. Lee, K. S. Kang, C. S. Park, J. W. Kim, and Y. H. Kim, "Effect of additives on redox behavior of iron oxide for chemical hydrogen storage," Journal of Industrial and Engineering Chemistry, vol. 14, no. 2, pp. 252-260, 2008.

[10] Y. H. Kim, H. S. Je, E. J. Kang, S. G. Lee, and C. S. Park, "Hydrogen storage and release by redox reaction of iron oxide medium with Mo and $\mathrm{Zr}$ additives," Advanced Materials Research, vol. 347-353, pp. 3317-3320, 2012.

[11] D. H. Lee, K. S. Cha, Y. S. Lee, K. S. Kang, C. S. Park, and Y. H. Kim, "Effects of $\mathrm{CeO}_{2}$ additive on redox characteristics of Fe-based mixed oxide mediums for storage and production of hydrogen," International Journal of Hydrogen Energy, vol. 34, no. 3, pp. 1417-1422, 2009.

[12] H. S. Kim, K. S. Cha, B. K. Yoo et al., "Chemical hydrogen storage and release properties using redox reaction over the $\mathrm{Cu}$ added $\mathrm{Fe} / \mathrm{Ce} / \mathrm{Zr}$ mixed oxide medium," Journal of Industrial and Engineering Chemistry, vol. 16, no. 1, pp. 81-86, 2010.

[13] M. Labaki, S. Siffert, J.-F. Lamonier, E. A. Zhilinskaya, and A. Aboukaïs, "Total oxidation of propene and toluene in the presence of zirconia doped by copper and yttrium: role of anionic vacancies," Applied Catalysis B, vol. 43, no. 3, pp. 261-271, 2003.

[14] J. Zhu, J. G. Van Ommen, H. J. M. Bouwmeester, and L. Lefferts, "Activation of $\mathrm{O}_{2}$ and $\mathrm{CH}_{4}$ on yttrium-stabilized zirconia for the partial oxidation of methane to synthesis gas," Journal of Catalysis, vol. 233, no. 2, pp. 434-441, 2005.

[15] M. Ishida, H. Jin, and T. Okamoto, "A fundamental study of a new kind of medium material for chemical-looping combustion," Energy and Fuels, vol. 10, no. 4, pp. 958-963, 1996.

[16] H. Y. Lin, Y. W. Chen, and C. Li, "The mechanism of reduction of iron oxide by hydrogen," Thermochimica Acta, vol. 400, no. 1-2, pp. 61-67, 2003.

[17] H. S. Je, E. J. Kang, S. G. Lee, C. S. Park, and Y. H. Kim, "Hydrogen storage and release by redox reaction of $\mathrm{Fe} / \mathrm{Zr} / \mathrm{Mo}$ mixed oxide mediums," Transactions of the Korean Hydrogen and New Energy Society, vol. 22, no. 5, pp. 616-624, 2011. 

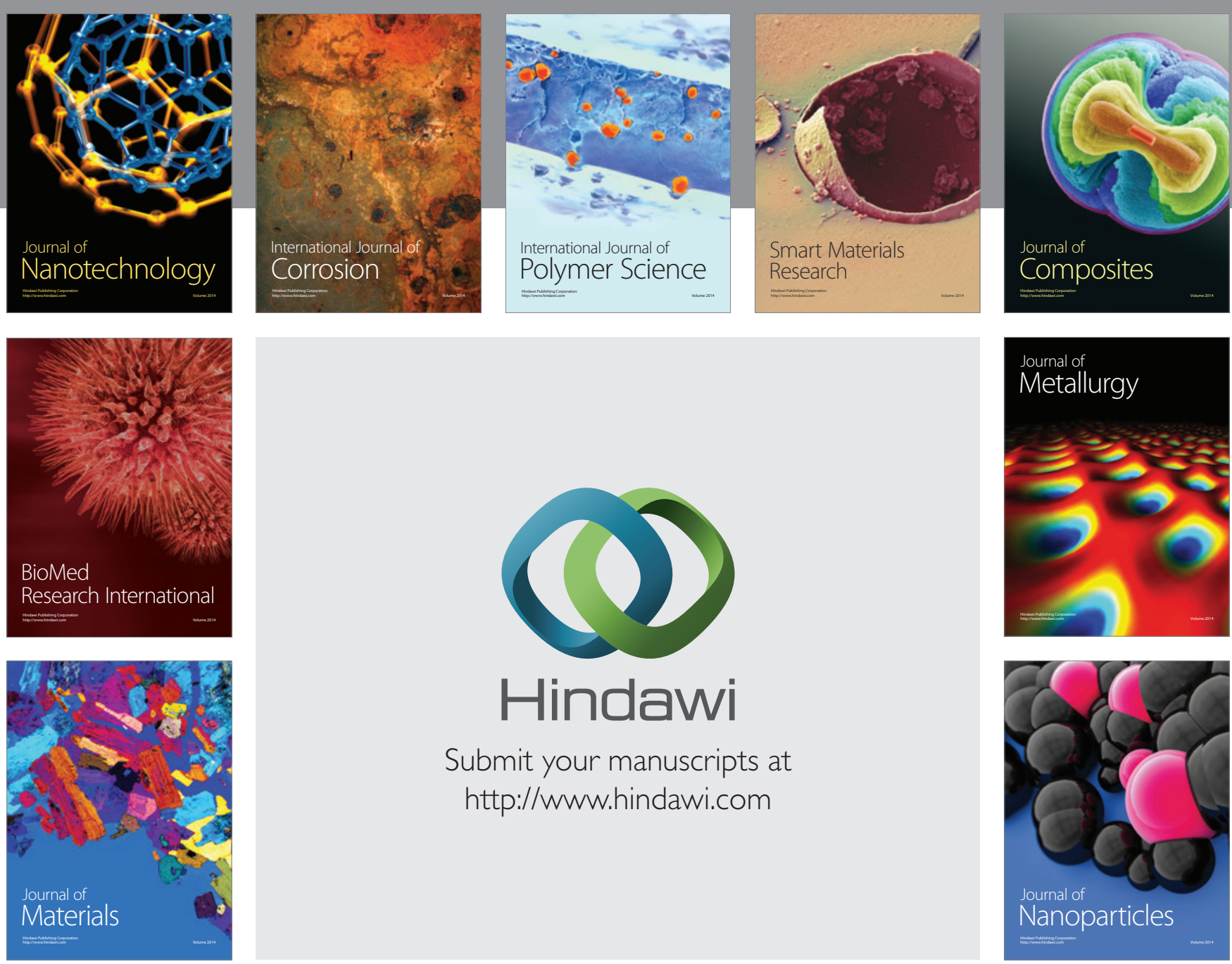

Submit your manuscripts at http://www.hindawi.com
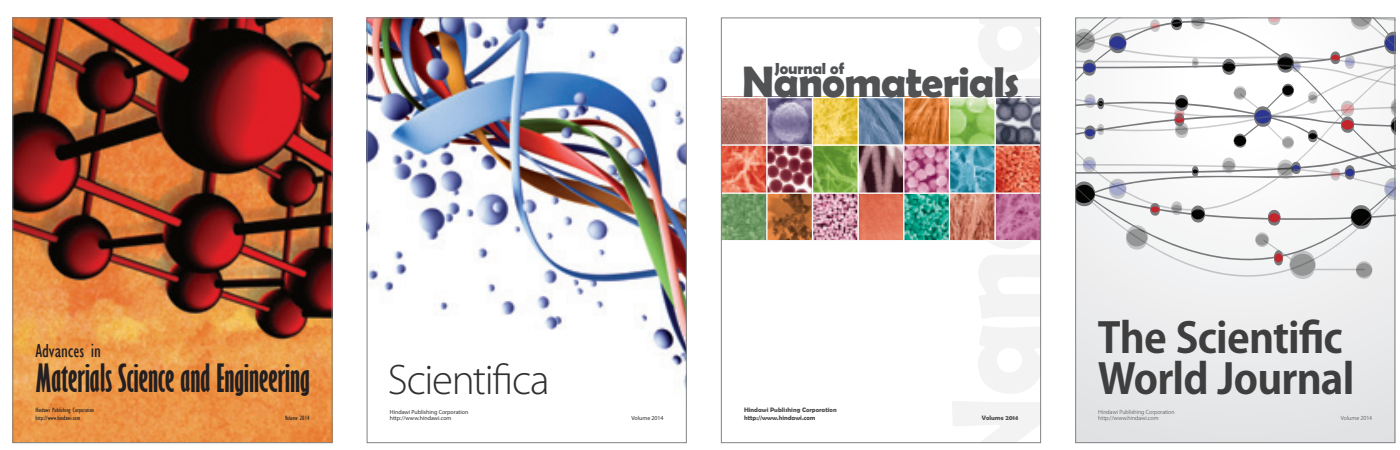

\section{The Scientific World Journal}
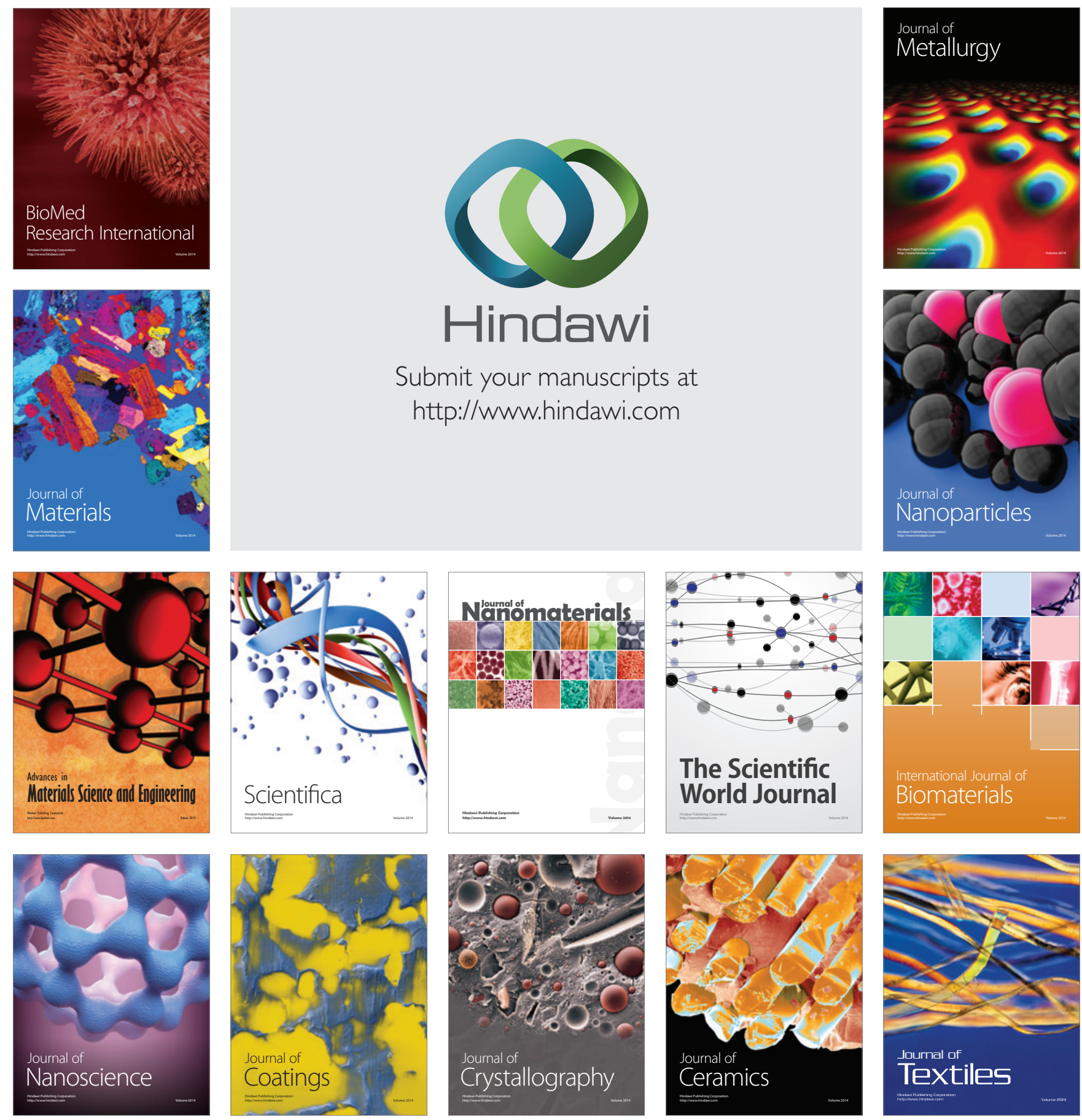